\title{
Beneficial effect of pentoxifylline into the testis of rats in an experimental model of unilateral hindlimb ischemia/ reperfusion injury
}

\author{
Mohammad Ashrafzadeh Takhtfooladi ${ }^{1}$, Fariborz Moayer ${ }^{2}$, Hamed Ashrafzadeh Takhtfooladi ${ }^{2}$ \\ ${ }^{1}$ Young Researchers and Elites Club, Science and Research Branch, Islamic Azad University, Tehran, Iran; \\ ${ }^{2}$ Department of Pathobiology, College of Veterinary Medicine, Karaj Branch, Islamic Azad University, \\ Alborz, Iran
}

\section{ABSTRACT}

Objective: The objective of the present study was to investigate the role of pentoxifylline (PTX) on remote testicular injury caused by unilateral hind limb ischemia/reperfusion of rats.

Materials and Methods: Twenty healthy male Wistar rats were allocated randomly into two groups: ischemia/reperfusion (IR group) and ischemia/reperfusion + pentoxifylline (IR+PTX group). Ischemia was induced by placement of a rubber tourniquet at the greater trochanter for $2 \mathrm{~h}$. Rats in IR+PTX group received PTX (40 mg/kg IP) before the reperfusion period. At $24 \mathrm{~h}$ after reperfusion, testes were removed and levels of superoxide dismutase (SOD), malondialdehyde (MDA), catalase (CAT) and myeloperoxidase (MPO) activity were determined in testicular tissues. Three rats of each group were used for wet/ dry weight ratio measurement. Testicular tissues were also examined histopathologically under light microscopy.

Results: Activities of SOD and CAT in testicular tissues were decreased by ischemia/ reperfusion $(\mathrm{P}<0.05)$. Significantly increased MDA levels in testicular tissues were decreased by PTX treatment $(\mathrm{P}<0.05)$. MPO activity in testicular tissues in the IR group was significantly higher than in the $\mathrm{IR}+\mathrm{PTX}$ group $(\mathrm{P}<0.05)$. The wet/dry weight ratio of testicular tissues in the IR group was significantly higher than in the IR+PTX group $(\mathrm{P}<0.05)$. Histopathologically, there was a statistically significant difference between two groups $(\mathrm{P}<0.05)$.

Conclusions: According to histological and biochemical findings, we conclude that PTX has preventive effects in the testicular injury induced by hind limb ischemia/reperfusion.

\section{ARTICLE INFO}

\section{Key words:}

Pentoxifylline; Hindlimb;

Ischemia; Reperfusion;

Testicular Diseases;

Oxidative Stress

Int Braz J Urol. 2015; 41: 576-83

Submitted for publication:

May 30, 2014

Accepted after revision:

October 10, 2014

\section{INTRODUCTION}

Hind limb ischemia/reperfusion injury may occur clinically after a release of tourniquets during orthopedic surgery, or extrication of a trauma victim who is compressed with a heavy weight for a prolonged period (crush syndrome). Several reports have indicated that the pathophysiology of the injury varies according to the duration and grade of the ischemia (1-3). It is well recognized that sustained ischemia can induce cell death and tissue necrosis, which are mainly caused by energy insufficiency. Many studies have shown that tissue injury in many organs occurs not only during the ischemic period but also in the reperfusion period. Skeletal muscle ischemia/reperfusion 
is associated with a systemic inflammatory response and determines the effect on remote organs (liver, lung, kidney, myocardium and testis) structure and function (4-9). The development of remote organ dysfunction was observed only following reperfusion, which implies that humoral and/or cellular mediators produced locally in the limb were responsible for mediating remote organ injury (10-12).

Pentoxifylline (PTX) is a methylxanthine derivative with multiple hemorheologic properties. PTX through effects of increasing intracellular cyclic AMP on red blood cells improve the oxygen delivery to ischemic tissues and also increases the cyclic AMP on polymorph nuclear leukocytes and decreases oxygen free radical production (10, 13-16). In addition, PTX limit the inflammatory response with reduction in cellular activation, phagocytosis and endothelium adhesion. There are evidences that PTX also reduces the nitric oxide destruction (15). Recent studies have indicated that PTX improves ischemia/reperfusion injury in many organs (17-19). However, the effects of PTX on remote testicular injury caused by skeletal muscle ischemia/reperfusion are not clear. The objective of the present study was to investigate the role of PTX on remote testicular injury caused by unilateral hind limb ischemia/reperfusion of rats. For this purpose, the biochemical and pathological effects of skeletal muscle ischemia/reperfusion and PTX in testicular tissues of rats have been investigated. The results of our investigation would help to clarify the potential importance of the use of PTX in situations of oxidative damage. These findings may encourage the use of antioxidants to reduce remote organ injury after skeletal muscle ischemia/reperfusion.

\section{MATERIALS AND METHODS}

\section{Animals}

The study was conducted on 20 healthy male Wistar rats, 12-16 weeks old and weighing between 270-300g. All rats of this study were kept according to the norms of the Islamic Azad University College of Veterinary Medicine Tehran Iran laboratory of animal experimentations; this investigation was approved by the Committee of
Ethics in Research with animals of Islamic Azad University. The study was designed so as to minimize the number of animals required for the experiments. The rats were housed in individual cages under temperature controlled standard conditions, $12 \mathrm{~h} / 12 \mathrm{~h}$ light/dark cycle with free access to standard rodent food and filtrated tap water.

\section{Experimental Design}

The animals were allocated randomly into two experimental groups of ten rats each as follows: ischemia/reperfusion (IR group) and ischemia/reperfusion + pentoxifylline (IR+PTX group). Anesthesia was induced with a mixture of ketamine and xylazine $(50 \mathrm{mg} / \mathrm{kg}$ and $10 \mathrm{mg} / \mathrm{kg}$, respectively) via intramuscular injection. The level of anesthesia was continuously monitored by observing the respiratory patterns and toe pinch reflex. After the induction of anesthesia, fur was completely removed from left hind limbs with an electric shaver to facilitate the measurement of limb perfusion. Unilateral hind limb ischemia was induced by placing an orthodontic rubber band at the hip joint. Before using the tourniquet, 250 IU of heparin was administered via the jugular vein to prevent clotting. The animals were kept anesthetized throughout the duration of ischemic period with additional anesthetic doses as needed. Body temperature was maintained with a heating pad whilst the animals were under anesthesia. In IR+PTX group, pentoxifylline (40 $\mathrm{mg} / \mathrm{kg}$ ) was injected intraperitoneally immediately before reperfusion. Pentoxifylline tablets were dissolved in normal saline as explained in previous studies (20). The analgesic nalbuphine hydrochloride (2 $\mathrm{mg} / \mathrm{kg}$ ) was used via subcutaneous during observation time. After $24 \mathrm{~h}$ of reperfusion, all animals were anesthetized again with the same mixture and a longitudinal incision of approximately $2 \mathrm{~cm}$ was made to the scrotal raphe for bilateral orchiectomies (a procedure involving cord clamping and hemostasis). Three rats of each group were used for wet/dry weight ratio measurement. Right testes of seven rats were processed for histopathological examination and left testes were washed with normal saline and stored in a $-80^{\circ} \mathrm{C}$ refrigerator for the evaluation of biochemical parameters. Then the rats were euthanized with an 
overdose of intraperitoneal pentobarbital by injection $(300 \mathrm{mg} / \mathrm{kg})$.

\section{nates}

Preparation of Testicular Tissue Homoge-

The left testicular tissues were washed three times in cold normal saline solution (0.9\%). Then, the tissues were homogenized in ice-cold Tris- $\mathrm{HCl}$ buffer solution, within a homogenizer for $2 \mathrm{~min}$ at $11200 \times \mathrm{g}$. The homogenate was centrifuged at $3500 \times \mathrm{x}$ for $60 \mathrm{~min}$ and a supernatant was obtained. The levels of MPO were determined in the supernatant, and MDA levels were studied in the homogenate. For a further extraction procedure, the supernatant was extracted in ethanol/ chloroform mixture (5/3 v/v). After a second centrifugation at $3500 \times \mathrm{g}$ for $20 \mathrm{~min}$, the clear upper layer was taken and used for SOD activity determination (21).

\section{BIOCHEMICAL ASSAYS}

\section{Measurement of SOD Activity}

The principle of the SOD activity determination method was based on the inhibition of nitroblue tetrazolium reduction described by Sun et al. (22) and modified by Durak et al. (23). One unit of SOD was defined as the enzyme activity causing 50\% inhibition in the nitroblue tetrazolium reduction rate. The SOD activity was expressed as units per mg tissue protein.

\section{Measurement of MDA levels}

The MDA levels in testicular tissues were analyzed by a method based on the reaction with thiobarbituric acid at $95^{\circ} \mathrm{C}(24)$. In the thiobarbituric acid test reaction, MDA or MDA-like substances and thiobarbituric acid react together to produce a pink pigment with an absorption maximum of $532 \mathrm{~nm}$. The results were expressed as nanomol per gram wet tissue (nmoL/g tissue).

\section{Measurement of CAT activity}

CAT activity was determined according to Aebi's method (25). The principle of the assay is based on determination of the rate constant $\mathrm{k}\left(\mathrm{s}^{-}\right.$ 1) of $\mathrm{H}_{2} \mathrm{O}_{2}$ decomposition at 240nm. Results were expressed as $k$ (rate constant) per gram of protein.

\section{Measurement of MPO activity}

Testicular injury was quantified by measuring testicular MPO activity, the activity of infiltrated polymorphonuclear leukocytes, using a protocol modified from a previous report (26). MPO activity was determined after adding 0-dianisidine dihydrochloride and hydrogen peroxide. The MPO activity was expressed as units per gram tissue.

\section{Wet/dry weight assay}

The wet/dry weight ratio, the tissue edema index, was measured to evaluate testicular injury. Briefly, freshly harvested testes were weighed, placed in an oven for $24 \mathrm{~h}$ at $60^{\circ} \mathrm{C}$ and weighed again when dry (26). The wet/dry weight ratio was then calculated.

\section{HISTOPATHOLOGICAL EVALUATION}

The right extracted testes were immediately placed into 10\% neutral formaldehyde solution. The tissue specimens were placed in paraffin blocks, sectioned at $5 \mu \mathrm{m}$, and stained with hematoxylin and eosin (H\&E) for light microscopic analysis. An experienced pathologist, who was blinded to the experiment and data, examined the samples histopathologically. The histological parameters were scored according to Cosentino et al. (27) classification as follows: Grade-I: Showed normal testicular architecture with an orderly, arrangement of germinal cells; Grade-II: Injury showed less orderly, non-cohesive germinal cells and closely packed seminiferous tubules;

Grade-III: Injury exhibited disordered sloughed germinal cells with shrunken pyknotic nuclei and less distinct seminiferous tubule borders;

Grade-IV: Injury defined seminiferous tubules that were closely packed with coagulative necrosis of the germinal cells.

\section{Statistical analysis}

Analyses were performed by using commercial SPSS software for Windows version 18. Kruskal-Wallis test was used to compare the biochemical and histopathological parameters between groups. When Kruskal-Wallis test results were 
significant, Bonferroni adjusted Mann-Whitney U test was used in the paired comparison. Data are shown as the mean \pm standard deviation with significance considered at 0.05 .

\section{RESULTS}

The experimental procedure was well tolerated and no animal died during the experiment. One of the most interesting observations at the histopathological examination of the testicular tissues is the presence of sloughed germinal cells within the seminiferous tubules and disorganization in rat testes after the unilateral hind limb ischemia/reperfusion. The testicular injury score increased significantly in the IR group compared with the IR+PTX group $(\mathrm{P}<0.05)$ (Table-1). In the IR group, coagulative necrosis with loss of seminiferous tubule epithelium, edema and sloughed germinal cells were predominant features in sections (Figure-1). However, the rats in the IR+PTX group had essentially normal seminiferous tubule morphology (Figure-2).

Activities of SOD and CAT in testicular tissues were decreased by ischemia/reperfusion, but administration of PTX increased these levels $(\mathrm{P}<0.05)$ (Table-1). The tissue levels of MDA increased in the IR group in comparison to the IR+PTX group (Table-1). MP0 activity in testicular tissues in the IR group was significantly higher than in the IR+PTX group $(\mathrm{P}<0.05)$ (Table-1). The wet/dry weight ratio of testicular tissues in the IR group was significantly higher than in the IR+PTX group $(\mathrm{P}<0.05)($ Table-1)

\section{DISCUSSION}

The systemic inflammatory response syndrome is a consequence of many conditions, such as surgery, trauma, burn, shock, or bacterial infection (28), that results in the development of potentially fatal complication known as multiple organ dysfunction syndrome. Hind limb ischemia/ reperfusion has been extensively used in our laboratory as a model of systemic inflammatory response syndrome, which closely resembles the acute traumatic and ischemic insult seen in systemic inflammatory response syndrome patients (29). It has been demonstrated that hind limb ischemia/ reperfusion causes cellular injury in remote organs (kidney, lung, and myocardium) and contributes to the development of multiple organ dysfunction syndrome $(5,29)$. As far as we know, there are only a few reports demonstrating testicular remote injury following muscle ischemia/reperfusion injury (8). The results of Takhtfooladi et al. (8) indicated that skeletal muscle ischemia/reperfusion induces severe testicular damage and $\mathrm{N}$-acetylcysteine has protective effects on testicular injury after hind limb ischemia/reperfusion. Their data supported this view that temporary occlusion of the femoral artery induced testicular injury in rats (8). Previous studies indicate that inflammatory response and injury to remote organs can be caused by the systemic release of the pro-inflammatory mediators and free oxygen radicals upon reperfusion of ischemic limbs $(5,30)$. Despite decades of research

Table 1 - The tissue CAT and MPO activities and levels of SOD and MDA in testicular tissues and score of testicular histological changes and muscle wet/dried weight (W/D) ratio.

\begin{tabular}{lcc}
\hline & Ischemia/Reperfusion & Ischemia/Reperfusion + Pentoxifylline \\
\hline SOD (U/mg protein) & $4.016 \pm 0.28$ & $8.12 \pm 0.13^{*}$ \\
CAT (K/g protein) & $81.03 \pm 4.17$ & $98.10 \pm 2.73^{*}$ \\
MPO (U/g tissue) & $1.03 \pm 0.20$ & $0.61 \pm 0.08^{*}$ \\
MDA (nmoL/g tissue) & $2.74 \pm 0.33$ & $1.85 \pm 0.21^{*}$ \\
Histological Grading & $2.30 \pm 0.67$ & $1.40 \pm 0.51^{*}$ \\
W/D Ratio & $2.20 \pm 0.13$ & $1.64 \pm 0.09^{*}$ \\
\hline
\end{tabular}

${ }^{*} \mathrm{P}<0.05$ compared with the ischemia-reperfusion group 
Figure 1 - Light microscopic view of testis tissues from IR group showing coagulative necrosis with loss of seminiferous tubule epithelium, edema and sloughed germinal cells. H\&E staining; magnification of $10 \times 10$.

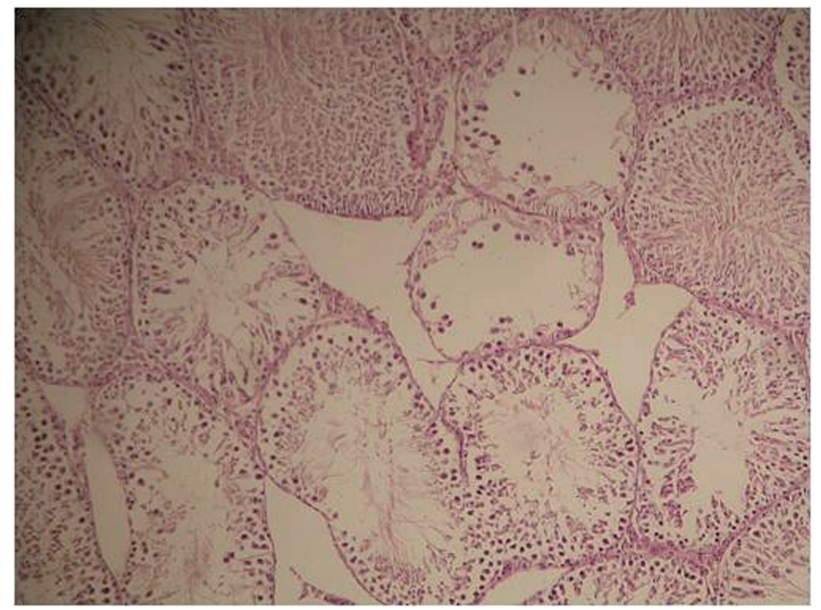

in this area, ischemia/reperfusion injury remains a clinically challenging problem.

PTX is one of the phosphodiesterase inhibitors that have been reported to increase intracellular cyclic AMP and reduce superoxide anion production by both monocytes and polymorphonuclear cells dose dependently in vitro (31). Endres et al. (32) indicated that PTX led to a marked increase in cyclic AMP levels, whereas cyclic GMP levels were only marginally elevated in lipopolysaccharide stimulated human monocytes. PTX has received considerable attention with respect to its action on leukocytes in many organs (33-35). Reignier et al. (19) reported that after reperfusion, myeloperoxidase activity and blood neutrophil count were lower with PTX than with saline, and changes in the filtration coefficient were correlated to the percent changes in blood neutrophils during reperfusion. They suggested that this effect may be mainly caused by a decrease in sequestration of neutrophils in the lung during reperfusion. Their group also reported that PTX prevented endothelial injury during ischemia/reperfusion by decreasing neutrophil sequestration in isolated perfused rat and rabbit lungs and in pigs after left lung allotransplantation (33).

Previous studies have also confirmed the potential antioxidant effects of PTX (36-38). Recently administered PTX was shown to protect against ischemia/reperfusion injuries in local and
Figure 2 - Light microscopic view of testis tissues from PTX treated group showing normal seminiferous tubule morphology with orderly arrangement of germinal cells. H\&E staining; magnification of $10 \times 10$.

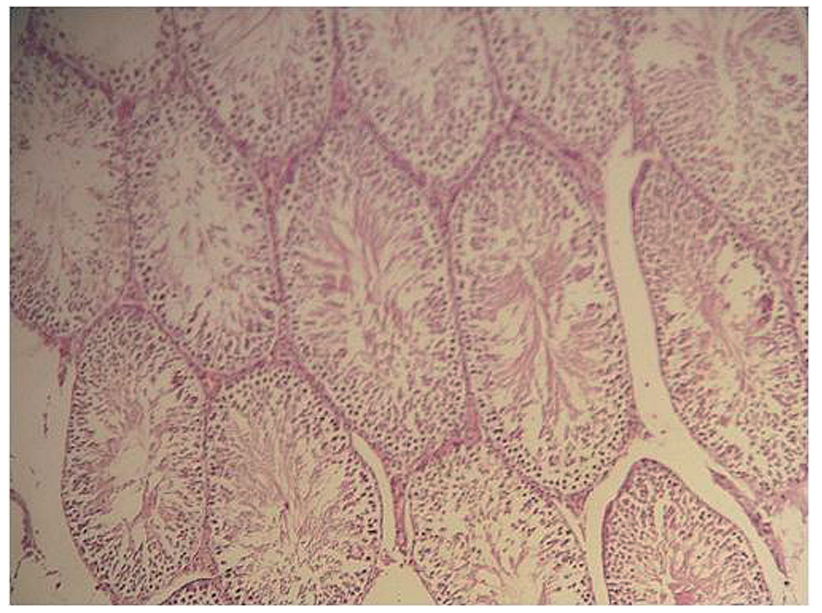

remote organs and it was suggested that this protective effect may be due to its ability to inhibit of free radical generation $(12,20)$. There is growing evidence regarding its beneficial effects in ameliorating testicular ischemia/reperfusion injury (39). In an experimental study Savas et al. (39) suggested that the administration of PTX at a dose of $50 \mathrm{mg} / \mathrm{kg} 15 \mathrm{~min}$. before spermatic cord torsion may have a protective effect in rat experimental testicular torsion/detorsion models. Their results suggest that pentoxifylline treatment attenuates reperfusion damage on both sides, possibly with its effects on blood flow and neutrophils (39). This observation was supported by Pozor et al. (40), who demonstrated that PTX may be a potential protective agent for preventing the negative changes related to oxidative stress in testicular injury caused by spermatic cord torsion in miniature horse stallions. However, the protective effect of PTX on testes from skeletal muscle ischemia/reperfusion injury has not been studied to date. In the current study, we tested the hypothesis that PTX could protect the testes from remote organ injury after skeletal muscle ischemia/reperfusion.

Oxidative stress is associated with an increased rate of cellular damage induced by oxygen and oxygen-derived oxidants, commonly known as reactive oxygen species $(41,42)$. The major targets of reactive oxygen species are membrane lipids, in a process known as lipid peroxidation. 
It is also acknowledged that testicular tissues and spermatozoa are very sensitive to reactive oxygen species attack and lipid peroxidation. The susceptibility of testicular tissues to oxidation is attributed to the high polyunsaturated fatty acid content of sperm membranes $(42,43)$. Many tissues contain powerful endogenous scavengers that provide protection against free radical damage, including SOD, CAT, glutathione peroxidase, ascorbic acid and $\alpha$-tocopherol (44). Sikka et al. (45) have reported that adequate levels of antioxidants such as SOD, CAT and possibly glutathione peroxidase and reductase, maintain the scavenging potential in gonads and seminal fluids, which is referred to as oxidative stress status. Tissue CAT and MPO activities, and SOD and MDA levels are considered to indicate oxidative stress. In the present study, SOD level and CAT activity were decreased significantly in IR group compared with IR+PTX group. The tissue MDA level and MPO activity in testes were increased significantly in IR group compared with IR+PTX group. According to the observations of this study, the histopathological injury score was significantly decreased in IR+PTX group compared with that of IR group. In the PTX treated group, histopathological features such as edema, congestion, hemorrhage, and necrosis of the germinal cells were markedly less than in IR group. The findings in this study indicate that reperfusion of the ischemic limb leads, within $24 \mathrm{~h}$ of reperfusion, to a systemic response as demonstrated by the biochemical and histological impairment of the testis. Also, data on CAT and MPO activity, and SOD and MDA levels suggested a protective effect of PTX against testicular remote injuries after unilateral hind limb ischemia/reperfusion. These data together with previous findings (39) confirm the potent anti-oxidation capacity of PTX. These data also support the concept that PTX may be an effective therapeutic adjunct to reperfusion injury. The clinical relevance of this manuscript refers to the previous use of PTX in situations requiring procedures ischemia with reperfusion to reduce or prevent distant organs damage. Therefore, the long-term effect of PTX warrants further investigation.

\section{CONCLUSIONS}

The results of this study showed that unilateral hind limb ischemia/reperfusion induced testicular injury in rats. Nevertheless, PTX administration significantly decreased testes injury induced by skeletal muscle ischemia/reperfusion according to our histological and biochemical findings. PTX is already in clinical use for the treatment of vascular diseases and these results suggest the possibility of clinical application of PTX in testicular remote organ injury following skeletal muscle ischemia/reperfusion. Further studies are needed to clarify clinical usefulness of this agent.

\section{CONFLICT OF INTEREST}

None declared.

\section{REFERENCES}

1. Oredsson S, Arlock P, Plate G, Qvarfordt P. Metabolic and electrophysiological changes in rabbit skeletal muscle during ischaemia and reperfusion. Eur J Surg.1993;159:3-8.

2. Roberts JP, Perry MO, Hariri RJ, Shires GT. Incomplete recovery of muscle cell function following partial but not complete ischemia. Circ Shock. 1985;17:253-8.

3. Kishi M, Tanaka H, Seiyama A, Takaoka M, Matsuoka T, Yoshioka T, et al. Pentoxifylline attenuates reperfusion injury in skeletal muscle after partial ischemia. Am J Physiol. 1998:274:H1435-42.

4. Coe DA, Freischlag JA, Johnson D, Mudaliar JH, Kosciesza SA, Traul DK, et al. Pentoxifylline prevents endothelial damage due to ischemia and reperfusion injury. J Surg Res. 1997;67:21-5.

5. Yassin MM, Harkin DW, Barros D'Sa AA, Halliday MI, Rowlands BJ. Lower limb ischemia-reperfusion injury triggers a systemic inflammatory response and multiple organ dysfunction. World J Surg. 2002;26:115-21.

6. Takhtfooladi MA, Jahanshahi A, Sotoudeh A, Jahanshahi G, Takhtfooladi HA, Aslani K. Effect of tramadol on lung injury induced by skeletal muscle ischemia-reperfusion: an experimental study. J Bras Pneumol. 2013;39:434-9.

7. Takhtfooladi MA, Jahanshahi A, Jahanshahi G, Sotoudeh A, Takhtfooladi HA, Khansari M. Protective effect of $\mathrm{N}$-acetylcysteine on kidney as a remote organ after skeletal muscle ischemia-reperfusion. Acta Cir Bras. 2012;27:611-5. 
8. Sotoudeh A, Takhtfooladi MA, Jahanshahi A, AsI AH, Takhtfooladi HA, Khansari M. Effect of $\mathrm{N}$-acetylcysteine on lung injury induced by skeletal muscle ischemiareperfusion. Histopathlogical study in rat model. Acta Cir Bras. 2012;27:168-71.

9. Takhtfooladi MA, Jahanshahi A, Sotoudeh A, Daneshi MH, Khansari M, Takhtfooladi HA. The antioxidant role of $\mathrm{N}$-acetylcysteine on the testicular remote injury after skeletal muscle ischemia and reperfusion in rats. Pol $\mathrm{J}$ Pathol. 2013;64:204-9.

10. Emrecan B, Tulukoglu E, Bozok S, Kestelli M, Onem G, Küpelioglu $A$, et al. Effects of Iloprost and pentoxifylline on renal ischemia-reperfusion in rabbit model. Eur J Med Res. 2006;11:295-9.

11. Gradl G, Gaida S, Finke B, Lindenblatt N, Gierer P, Menger $M D$, et al. Supernatant of traumatized muscle induces inflammation and pain, but not microcirculatory perfusion failure and apoptotic cell death. Shock. 2005;24:219-25.

12. Teruya R, Fagundes DJ, Oshima CT, Brasileiro JL, Marks G, Ynouye CM, et al. The effects of pentoxifylline into the kidneys of rats in a model of unilateral hindlimb ischemia/ reperfusion injury. Acta Cir Bras. 2008;23:29-35.

13. Stafford-Smith M. Evidence-based renal protection in cardiac surgery. Semin Cardiothorac Vasc Anesth. 2005;9:65-76.

14. Vadiei K, Brunner LJ, Luke DR. Effects of pentoxifylline in experimental acute renal failure. Kidney Int. 1989;36:466-70.

15. Dávila-Esqueda ME, Martínez-Morales F. Pentoxifylline diminishes the oxidative damage to renal tissue induced by streptozotocin in the rat. Exp Diabesity Res. 2004;5:245-51.

16. Gunduz Z, Canoz O, Per H, Dusunsel R, Poyrazoglu MH, Tez C, et al. The effects of pentoxifylline on diabetic renal changes in streptozotocin-induced diabetes mellitus. Ren Fail. 2004;26:597-605.

17. Adams JG Jr, Dhar A, Shukla SD, Silver D. Effect of pentoxifylline on tissue injury and platelet-activating factor production during ischemia-reperfusion injury. J Vasc Surg. 1995;21:742-8.

18. Horton JW, White DJ. Free radical scavengers prevent intestinal ischemia-reperfusion-mediated cardiac dysfunction. J Surg Res. 1993;55:282-9.

19. Reignier J, Mazmanian M, Detruit $\mathrm{H}$, Chapelier A, Weiss M, Libert JM, et al. Reduction of ischemia-reperfusion injury by pentoxifylline in the isolated rat lung. Paris-Sud University Lung Transplantation Group. Am J Respir Crit Care Med.1994;150:342-7.

20. Takhtfooladi H, Moayer F, Abarkar M: Effects of pentoxifylline on skeletal muscle inj ury induced by acute hindlimb ischaemia-reperfusion: a histopathological study in a rat model. Comp Clin Pathol. 2014; 24(3) In Press.

21. Parlaktas BS, Atilgan D, Gencten $Y$, Akbas A, Markoc F, Erdemir $F$, et al. The effects of carvedilol on ischemia-reperfusion injury in the rat testis. Int Braz J Urol. 2014;40:109-17.
22. Sun Y, Oberley LW, Li Y. A simple method for clinical assay of superoxide dismutase. Clin Chem. 1988;34:497-500.

23. Durak I, YurtarslanI Z, Canbolat O, Akyol O. A methodological approach to superoxide dismutase (SOD) activity assay based on inhibition of nitroblue tetrazolium (NBT) reduction. Clin Chim Acta. 1993;214:103-4.

24. Wasowicz W, Nève J, Peretz A. Optimized steps in fluorometric determination of thiobarbituric acid-reactive substances in serum: importance of extraction $\mathrm{pH}$ and influence of sample preservation and storage. Clin Chem. 1993;39:2522-6.

25. Aebi H. Catalase. In: Bergmeyer HU (ed.), Methods of Enzymatic Analysis. Academic Press, New York, 1974; pp. 673-7.

26. Yang $\mathrm{CH}$, Tsai PS, Wang TY, Huang CJ. Dexmedetomidineketamine combination mitigates acute lung injury in haemorrhagic shock rats. Resuscitation. 2009;80:1204-10.

27. Cosentino MJ, Nishida M, Rabinowitz R, Cockett AT. Histological changes occurring in the contralateral testes of prepubertal rats subjected to various durations of unilateral spermatic cord torsion. J Urol. 1985;133:906-11.

28. Carden DL, Granger DN. Pathophysiology of ischaemiareperfusion injury. J Pathol. 2000;190:255-66.

29. Wunder C, Brock RW, McCarter SD, Bihari A, Harris K, Eichelbrönner 0 , et al. Inhibition of haem oxygenase activity increases leukocyte accumulation in the liver following limb ischaemia-reperfusion in mice. J Physiol. 2002;540:1013-21.

30. Lawlor DK, Brock RW, Harris KA, Potter RF. Cytokines contribute to early hepatic parenchymal injury and microvascular dysfunction after bilateral hindlimb ischemia. J Vasc Surg. 1999;30:533-41.

31. Bessler H, Gilgal R, Djaldetti M, Zahavi I. Effect of pentoxifylline on the phagocytic activity, CAMP levels, and superoxide anion production by monocytes and polymorphonuclear cells. J Leukoc Biol. 1986;40:747-54.

32. Endres S, Fülle HJ, Sinha B, Stoll D, Dinarello CA, Gerzer R, et al. Cyclic nucleotides differentially regulate the synthesis of tumour necrosis factor-alpha and interleukin-1 beta by human mononuclear cells. Immunology. 1991;72:56-60.

33. Chapelier A, Reignier J, Mazmanian M, Detruit H, Dartevelle P, Parquin F,et al. Pentoxifylline and lung ischemia-reperfusion injury: application to lung transplantation. Université ParisSud Lung Transplant Group. J Cardiovasc Pharmacol. 1995;25,Suppl 2:S130-3.

34. Ciuffetti G, Mercuri M, Ott C, Lombardini R, Paltriccia R, Lupattelli $G$, et al. Use of pentoxifylline as an inhibitor of free radical generation in peripheral vascular disease. Results of a double-blind placebo-controlled study. Eur J Clin Pharmacol. 1991;41:511-5.

35. Seiffge $D$, Bissinger T, Kremer E, Laux V, Schleyerbach R. Inhibitory effects of pentoxifylline on LPS-induced leukocyte adhesion and macromolecular extravasation in the microcirculation. Inflamm Res. 1995;44:281-6. 
36. Bhat VB, Madyastha KM. Antioxidant and radical scavenging properties of 8-0xo derivatives of xanthine drugs pentoxifylline and lisofylline. Biochem Biophys Res Commun. 2001;288:1212-7.

37. Horvath B, Marton Z, Halmosi R, Alexy T, Szapary L, Vekasi J, et al. In vitro antioxidant properties of pentoxifylline, piracetam, and vinpocetine. Clin Neuropharmacol. 2002;25:37-42.

38. Lin SL, Chen YM, Chien CT, Chiang WC, Tsai CC, Tsai TJ. Pentoxifylline attenuated the renal disease progression in rats with remnant kidney. J Am Soc Nephrol. 2002;13:2916-29.

39. Savas C, Dindar H, Bilgehan A, Ataoglu O, Yucesan S. Pentoxifylline attenuates reperfusion injury in testicular torsion. Scand J Urol Nephrol. 2002;36:65-70.

40. Pozor MA, Muehlhaus J, King A, Macpherson ML, Troedsson $\mathrm{MH}$, Bailey CS. Effect of pentoxifylline treatment on testicular perfusion and semen quality in Miniature horse stallions. Theriogenology. 2011;76:1027-35.
41. Tinkel J, Hassanain H, Khouri SJ. Cardiovascular antioxidant therapy: a review of supplements, pharmacotherapies, and mechanisms. Cardiol Rev. 2012;20:77-83.

42. Erdemir F, Atilgan D, Firat F, Markoc F, Parlaktas BS, Sogut E. The effect of sertraline, paroxetine, fluoxetine and escitalopram on testicular tissue and oxidative stress parameters in rats. Int Braz J Urol. 2014;40:100-8.

43. Jungwirth A, Giwercman A, Tournaye H, Diemer T, Kopa Z, Dohle $G$, et al. European Association of Urology guidelines on Male Infertility: the 2012 update. Eur Urol. 2012;62:324-32.

44. Demopoulos HB, Flamm ES, Pietronigro DD, Seligman ML. The free radical pathology and the microcirculation in the major central nervous system disorders. Acta Physiol Scand Suppl. 1980;492:91-119.

45. Sikka SC, Rajasekaran M, Hellstrom WJ. Role of oxidative stress and antioxidants in male infertility. J Androl. 1995;16:464-8.

Correspondence address: Mohammad Ashrafzadeh Takhtfooladi, DVM, DVSc Young Researchers and Elites Club Science and Research Branch Islamic Azad University, Tehran, Iran Fax: +98 311 786-0211 E-mail: dr_ashrafzadeh@yahoo.com 